\title{
LA SIGNIFICACIÓN HUMANA Y EL TODO. LECTURAS Y FILIACIONES TEOLOGICAS EN FREUD Y LACAN
}

\author{
The Human Significance and the Whole. \\ Theological Readings and Affiliations in Freud and Lacan.
}

Joaquin Cardoso*

Recepción: 18-02-2018

Aceptación: 23-05-2018

\section{RESUMEN}

La pregunta por la significación humana y el todo conoció un trayecto filosófico tan vasto que no eximió siquiera a pensadores "ateos" como los materialistas históricos o los padres del psicoanálisis. Si bien sus objetivos eran diferentes, la genealogía de sus lecturas y sus deudas nos permiten ubicar en el marco teologal muchísimos aspectos de su práctica teórica. Por este motivo, el siguiente artículo será el primero de algunos trabajos tendientes a identificar las influencias de la religión y la teología en autores ligados al pensamiento del siglo XX, eminentemente laico. En esta misma perspectiva buscamos ubicar la pregunta por el Uno y por el Todo en el centro de la filosofía dialéctica, para lo cual tomamos como pretexto el libro "La gracia y el deseo. San Agustín, Pascal, Lacan" de Sara Vassallo.

\section{PALABRAS CLAVE}

Dios, teología, gracia, deseo, sujeto, voluntad

\begin{abstract}
The question of human significance and the whole knew a philosophical course so vast that it did not exempt even "atheist" thinkers, like the historical materialists or the parents of psychoanalysis. Although their objectives were different, the genealogy of their readings and their respective intellectual debts allow us to locate within the theological framework many aspects of their theoretical practice. For this reason, the following article will be the first of some works aimed at identifying the influence of religion and theology on authors linked to the eminently secular thought of the twentieth century. From this same perspective, we seek to locate the question for the One and for the All at the center of dialectical philosophy, for which we take as an excuse the book "Grace and desire. San Agustin, Pascal, Lacan" by Sara Vassallo.
\end{abstract}

\section{Keywords:}

God, theology, grace, desire, will

* Docente de la Universidad Nacional del Arte - UNA- Argentina: joaquin.cardoso@gmail.com 


\section{Presentación}

El siguiente trabajo, de forma breve, reflexionará sobre algunas nociones de Dios organizado en polémicas antiguas (Agustín y Pelagio) sin dejar de mencionar algunos aportes de Freud y Lacan en el tema. Nos parece de suma importancia que quienes se posicionan desde el punto de vista del pensamiento crítico en general, en tanto pretensión no de totalidad, pero sí de abordaje sumario de múltiples facetas, no desconozca todo un campo o zona del pensamiento -y del sentimiento- al que se adhieren millones de personas en todo el mundo.

\section{Punta de lanza}

En el libro El inconsciente político, que en habla hispana se conoce como Documentos de cultura, documentos de barbarie, el pensador norteamericano Fredric Jameson, hace ya 30 años, describía hacia el final del libro una frase de Marx sobre el modo de producción asiático, que, según él, contenía el germen de una posibilidad de pensar la religión y lo religioso desde el marxismo pero que no se desarrolló (con profundidad) ni en el autor del Capital, ni en sus herederos.

La más urgente tarea, siempre de acuerdo al autor citado, era consolidar categorías que puedan pensar la "conciencia" desde un punto de vista colectivo sin recurrir para ello a terminología proveniente de la experiencia individual (por ejemplo "sujeto"):

En la mayoría de las formas territoriales asiáticas, la unidad comprensiva que se encuentra por encima de todas esas pequeñas comunidades aparece como el más alto propietario o como el único propietario. Debido a que la unidad es el propietario real y la presuposición real de la propiedad comunal... la relación del individuo con las condiciones naturales del trabajo de la reproducción...aparece mediatizada para él a través de una cesión hecha por la unidad total -una unidad que se realiza en la forma del déspota, el padre de muchas comunidades". (destacado en el original, 1989, p. 238)

Este disparador lo ponemos como ejemplo simplemente porque Jameson con esto quería mostrar que Durkheim y la sociología "ahistórica" había tomado el tema de la significación colectiva (nacionalismos y religiones) con mucho más método que el marxismo, y podríamos agregar nosotros que el pensamiento denominado crítico, si bien se posa en la cuestión teológica en la producción editorial del último decenio, no pasa de ser meras reflexiones filosóficas tendientes a problematizar la nueva ola de fundamentalismos (es decir, que los guían motivos diferentes ${ }^{1}$ ).

Agrega Jameson "tanto peor para el marxismo", como considerando que la pregunta sobre el Todo, sobre el Uno y sobre la significación humana que construye sentido por encima de las relaciones interpersonales, es un valor que no hay que desestimar, sobre todo cuando se tiene en mente la asimilación por parte de las masas de conceptos de conciencia social o incluso de simbolismos humanos universales.

Este artículo, tomando el desafío casi marginal y silenciado de Jameson, intenta dar cuenta de algunos pocos aspectos de ese vínculo complejo entre filosofía y

1 También a Durkheim lo guiaban objetivos diferentes. En este listado actual podemos mencionar, al pasar, a Zizek, Agamben, Espósito, etc. 
teología. Con una inevitable arbitrariedad en la selección del material analizado, pretendemos colocar tres puntos de reflexión sobre la herencia teológica en algunos pensadores identificados históricamente con la laicidad, y plantear preguntas de apertura a zonas del pensamiento que, aún de forma mutada, siguen operando en pleno siglo XXI.

No es nueva la reflexión, hasta podríamos consignar una posible genealogía (Engels, Kautsky, Luxemburgo) a Walter Benjamin ${ }^{2}$ y su estudio sobre el mito, en tanto apodíctico y configurador de sentido incuestionable en una sociedad, que a juzgar por él regresa en la predominancia conviviendo con las tendencias más modernas. Por su "eterno retorno3" y por su circularidad, como veremos al final del texto, él tuvo el cuidado de darle importancia al asunto del "enano teológico" ${ }^{4}$, sencillamente porque si operamos negándolo barremos con los fundamentos básicos de la occidentalidad -inclusive y, sobre todo, allí donde se pretende negarla.

Si bien este texto no desarrollará los autores citados en esta introducción, sî asumirá la polémica sobre las lecturas de otros identificados con el proceso secularizado del siglo XX. Quedará para el futuro analizar y problematizar estas influencias en autores destacados identificados con el materialismo dialéctico.
Como primer paso, trabajaremos algunas de las nociones agustinianas colocándolas en el marco del aporte al pensamiento humano que generaron con su consecuente influencia teórica. Asimismo, partiremos de dos de los máximos exponentes del psicoanálisis para identificar en ellos las estelas de incidencia de figuras propias de la teología como Agustín y Pascal.

\section{La significación humana y el todo}

La diatriba entre "Dios como lo Uno Absoluto" y Dios trinitario, adquirió notorias implicancias en la historia de la filosofía, desde Agustín contra Pelagio, hasta Lacan y su "Kant vs. Sade" o "Discurso a los católicos", entre otros, sin dejar de mencionar en ese recorrido a Freud.

\section{Agustín}

Para este apartado tomaremos las enumeraciones polémicas descriptas en el libro de Sara Vassallo El deseo y la gracia del 2015, que, si bien no es el único, estudia las concepciones sobre el Otro en Lacan y su deuda genealógica formativa en San Agustín.

En dicho libro, a Vassallo le interesa (dicho en términos muy generales), pensar sobre la relación del sujeto con el Otro, en un anudamiento que no por contraponer conceptos antinómicos se eliminan entre

2 Walter Benjamin fue un filósofo judío alemán que desarrolló parte de su obra inscripto en la denominada Escuela de Frankfurt, que albergó pensadores de la talla de Gyorg Lukacs, Erich Fromm, Theodor Adorno, entre otros. Su suicidio en 1940 conmocionó a la intelectualidad del mundo entero, y sus libros siguen siendo objeto de debate en la actualidad.

3 La afirmación de Nietzsche respecto del eterno retorno la retoma Eagleton: "Si el mito es un asunto de eterno retorno, entonces el retorno que más importa en la esfera del capitalismo monopolista es el eterno regreso de la mercancía. El capitalismo, en realidad, tiene una historia; pero la dinámica de ese desarrollo, como Marx destacaba con ironía, es la recreación perpetua de su propia estructura «eterna». Cada acto de intercambio de mercancía es a la vez algo diferenciado de manera única y una monótona repetición de la misma vieja historia" (2006: 394).

4 De múltiple referencia, el enano teológico para Benjamin consistía, en sus tesis sobre filosofía de la historia, en el "alma" de un autómata -basado en la figura popularizada por Edgar Allan Poe, que, aunque regido por la racionalidad comprendía en su interior una condensación de sentido más propia de lo teológico (ver Tesis sobre la historia y otros fragmentos (2008), España: Itaca). 
sí. Para ello se vale de una profunda genealogía filosófica que va desde Agustín hasta Pascal pasando por un interludio en Sartre. Oponiéndose tanto a un determinismo causal-estructural (de un "llamado del Otro" que se presente como destino) como a un sujeto supuestamente libre de determinaciones, Vasallo somete a análisis todos los conceptos de dichos autores que pensaron este tema. En particular, y en el punto que nos ocupa en este apartado, el libre albedrío y la gracia, además de la voluntad.

Agustín polemiza con Pelagio por la significación humana de la voluntad porque si la criatura es un efecto de Dios, queda en ella un vacío que la separa del Otro. En ese vacío se inscribe la gracia. Vassallo cita a Agustín: "Aún cuando actuamos en contra de nosotros mismos, hacemos lo que queremos hacer" (2015, p. 22). Luego añade: "Esta paradoja central -motor de su pensamiento- se inscribe en contra del determinismo causal del deseo del Otro en el deseo del sujeto. San Agustín sostiene, en efecto, que la voluntad del Otro actúa en el sujeto pero que no por ello éste deja de ser responsable de sus acciones (para actuar, debe "consentir" a la voluntad del Otro". (p. 81). Luego de esta sentencia resume: "(...) es porque estamos alienados al significante que el significante puede liberarnos. Es porque estamos alienados al Otro que podemos ser sujetos. La libertad es la condición de la alienación". (p. 90).

Para Agustín, el dualismo "alma-cuerpo" no describe fielmente la encarnación del Otro en el sujeto, sino que le falta un tercero que anude las concepciones y lo encuentra en el concepto de voluntad. No es una voluntad libre enteramente o de indeterminaciones causales, sino que responde a la demanda del Otro, pero sabiendo.
El aporte de Agustín, rupturista dentro de la Iglesia y por encargo de la misma Iglesia, fue que al dualismo filosófico (al que ya hemos nombrado de "alma y cuerpo" podemos agregar también pecado/ley, Dios/hombre, Padre/hijo), le añade en la retórica el antagonismo por muchos analizado como oxímoron que como nudo enlaza los vocablos incorporando el "tres" (por ejemplo, en su majestuoso De la trinidad).

En un tramo en que Vassallo intenta entender las posibilidades de pensar un Dios carente de sustancia, pero al mismo tiempo "vacío" entre dos significantes, dice: Dios no aparece sólo en el lugar en que el sujeto no coincide consigo mismo sino en la formulación de un resto enigmático de esa noidentidad. Podríamos agregar nosotros, para abonar esta lectura de Agustín, el aporte de Eagleton cuando indica que "hay algo inhumano o impersonal en el centro del yo, que lo hace ser como es; mientras que para Agustín y Aquino el nombre de ese poder maravillosamente insondable es Dios, para los freudianos es el deseo y para Kant la ley moral" (2012, p.208) y en otro tramo "¿Qué es el deseo de lo Real sino lo que san Agustín y Kierkeegard conocían como fe?" (p. 278).

Otro momento del estudio que hace Vasallo remarca estas posiciones con el siguiente comentario: "En el hueco del Otro donde el sujeto va a buscar su plenitud sin encontrarla se esboza la cuestión de la fe" (p. 25) y luego: "(...) el Dios trino es sólo el iceberg de una estructura ternaria que atraviesa todas las elaboraciones textuales de Agustín (...) la antítesis se convierte en oxímoron, donde un tercero trabaja subterráneamente la relación puntual de oposición". (2015, pp. 46 y 48). 


\section{Freud y Lacan 5}

Para completar este breve ensayo que rescata aportes de pensadores identificados con el pensamiento complejo y alejados, en principio, de lo que parecieran ser auxilios dogmáticos o eclesiásticos, haremos un pequeño compendio de una mención de Freud a la discusión religiosa (que, dicho sea de paso, trabajó con más detenimiento en otros trabajos que por limitaciones obvias no podremos atender). También, con un trabajo del francés Jacques Le Brun y nuevamente Sara Vassallo tomaremos pocas pero contundentes frases de Lacan en cuanto a la cuestión de Dios, no por simples provocaciones descontextualizadas sino porque confirman una herencia "sanagustiniana" y además enriquece este aspecto sin obviarlo o minimizarlo (sino todo lo contrario) ${ }^{6}$.

\section{Freud}

(...) No conocer esta filiación y estructuración, y para decirlo todo, esta paternidad cultural necesaria que hay entre cierto giro del pensamiento que se ha producido en este punto sensible, en ese punto de fractura que se sitúa hacia el comienzo del siglo XVI y prolonga sus ondas poderosamente, de una forma visible hasta el medio y hasta el fin del siglo XVII, es algo que equivale a desconocer enteramente a qué tipo de problema se dirige la interrogación freudiana (Lacan, 1960).
Es conocido el aporte de Freud al entendimiento de la cuestión religiosa, no solamente a través de El porvenir de una ilusión, Tótem y tabú o Más allá del principio del placer, sino, y este libro es el que tomaremos nosotros, hacia el final de su vida con Moisés y la religión monoteísta. Como señala Milmaniene (2006, pp. 19-23), fue quizás la dedicatoria del padre de Freud a este en una Biblia de la niñez de Sigmund lo que-inconscientemente y a largo plazo, impulsó a Freud en sus escritos de vejez a "reconciliarse con la religión de su padre", sólo que con el impulso de la nueva praxis fundada por Sigmund.

Milmaniene lo sintetiza así:

Freud retoma así, instado por las reiteradas exhortaciones de su padre a través de un libro y una dedicatoria, los valores judíos de la iconoclastia monoteísta y la hegemonía del Verbo hecha acto responsable y los incorpora al discurso científico del psicoanálisis bajo el modo de la práctica del diálogo en transferencia con el Otro, lo que le permite trascender el goce de los síntomas y acceder así al universo desiderativo". (p. 21)

Sabemos que, en su Moisés, Freud coloca la virtual y polémica hipótesis de que Moisés era egipcio, y esa bastardía original funciona como punto nodal de comprensión del desarrollo monoteísta ulterior, que además confrontó visiones paganas del pasado con futuros

5 En tanto literatura que adquirió por su relevancia, el conocimiento y la disponibilidad "universal" en la cultura sobre todo de Occidente, tomaremos los textos de Freud y Lacan (pero también los que usamos como análisis de sus obras) con el indecoro de quien los toma en función de la explicación al tema que nos ocupa, aún sabiendo que sus finalidades clínicas nos rebasan y superan, asimismo la comprensión de sus premisas. Sólo a modo filosófico nos sirven estos componentes ilustrativos, además para resguardar y reivindicar muchas de sus genealogías conceptuales.

6 Solo por redundancia formal repetiremos que no desconocemos que los fines a los que aludía Lacan para tomar nociones agustinianas o cristianas, no se corresponden con peripecias filosóficas ni teológicas. Aún así creemos que coloca aportes de magnitud que exceden en el ejercicio de la clínica o el campo teórico del psicoanálisis. 
monoteístas de gran riqueza para la humanidad. Para este análisis tomaremos fragmentos del libro original y también un comentario de Richard Berstein al mismo libro. Ya veremos que Lacan, aunque en algún momento haya dicho que Freud sostenía un "cristianismo débil", se diferenció de aquél en tanto reivindicó el cristianismo como "la verdadera religión", mientras que Freud la consideró menor respecto del judaísmo.

Para Freud, la religión monoteísta se apoya sobre la base del asesinato del Padre primordial, y ese parricidio primigenio contribuye a la formación de una unidad social de gran cohesión que en forma de ritualizaciones se actualiza en el pueblo judío. Sin dejar de mencionar, por supuesto, tanto en el desarrollo de la ley mosaica como en el desenvolvimiento del pueblo judío, las categorías de trauma/ defensa/latencia/estallido de la neurosis/ retorno parcial de lo reprimido. Es decir, el monoteísmo como la aparición de la Ley en tanto pura exterioridad, o, en palabras de Milmaniene, "(...) a través de la comparecencia ante la trascendencia, signada por la invisibilización del emisor, sustraído de la representación y la mirada, pero presente como Voz" (2012, p. 13).

En este punto, Bernstein defiende una perspectiva de Freud que complejiza y asimila conceptualizaciones ligadas al problema religioso que amplían referencias que se han tenido sobre sus textos y que limitan la importancia del fenómeno:

Al menos tres probables asesinatos ocupan un sitio fundamental en la trama ideada por Freud sobre el desarrollo de la religión: el asesinato del padre primigenio, el asesinato de Moisés y el asesinato de Jesús. Aunque alegó que los últimos dos son repeticiones inconscientes del homicidio original, la reacción de cada uno de ellos tiene consecuencias muy diversas para la religión (...) la conjetura de Freud es incluso más ambiciosa, pues, según él, el asesinato del padre primigenio es el suceso formativo no sólo de la religión, sino también de la sociedad y de la ética". (p. 132)

Para Freud, con fines específicamente demostrativos de las necesidades y deseos psicológicos y costos psíquicos introducidos por la religión, consolida una línea cronológica dentro del monoteísmo que, luego del asesinato del Padre original, y la culpa establecida por los judíos en su asesinato posterior, "revive" en la religión del hijo, es decir el cristianismo: "(...) Hasta que al fin alguien de este pueblo judío halló, en la absolución de culpa de un agitador político-religioso, la ocasión con la cual una religión nueva, la cristiana, se desasió del judaísmo. Pablo, un judío romano de Tarso, aprehendió esta conciencia de culpa y la recondujo certeramente a su fuente en el acontecer histórico primordial. La llamó 'pecado original', era un crimen contra Dios que sólo se podía expiar mediante la muerte". (Freud, citado por Bernstein, 2002, p. 106)

Aun valorando la audacia de Saulo de Tarso (posteriormente San Pablo) en la universalización de los preceptos cristianos, Freud llama la atención sobre lo que considera una vulgarización de aspectos espirituales con el cristianismo, que no existía con el monoteísmo propio del pueblo judío, más espiritualizado. Sus palabras son: "(...) la nueva religión (el cristianismo) significaba, con referencia a la antigua, la judía, una regresión cultural, como es regla que suceda cuando irrumpen o son admitidas masas de nivel inferior. La religión cristiana no mantuvo la altura de espiritualización hasta la cual 
se había elevado el judaísmo". (Bernstein, 2002, p. 60)

\section{Lacan}

"El Otro, el Otro como lugar de la verdad, es el único lugar, irreductible por demás, que podemos dar al término del ser divino, al término Dios, para llamarlo por su nombre. Dios es propiamente el lugar donde, si se me permite el juego, se produce el dios - el dior- el decir. Por poco, el decir se hace Dios. Y en tanto se diga algo, allí estará la hipótesis de Dios" (Lacan, 1973)

Por el lado de Lacan, podemos aseverar junto a la psicoanalista Vassallo, que existe una profunda huella de autores ligados de un modo u otro a la Iglesia y lo religioso en cuanto a herencia teórica en el proceso de construcción teórica del psicoanalista francés. En palabras de Vasallo, "No sé si algún historiador de las religiones se ha hecho cargo de la increíble maniobra teórica por la cual Lacan lleva al terreno del psicoanálisis, bajo el nombre del sujeto del inconsciente, el yo o la primera persona en que habla el Dios hebreo, el que dice Yo soy el que soy, o lo que es lo mismo, el Dios de Abraham, de Isaac y de Jacob". (2015, p. 11). O bien, en términos de la misma autora, "(...) quedan anudados, tanto en el psicoanálisis como en la religión, la verdad, el sentido y lo real" (p. 135) y "Lacan ha insistido en que es imposible no ser creyente" (p.131).

Para abonar en ese sentido, Milmaniene expresa también puntos de acuerdo entre el discurso psicoanalítico y el bíblico: "(...) debemos consignar que en ambos registros se plantea la promoción del lenguaje como espacio privilegiado de subjetivación: en un caso, a través de la exposición del niño ante el Otro del deseo y la Ley, y en el otro, a través de la comparecencia ante la trascendencia signada por la invisibilidad del emisor, sustraído de la representación y la mirada". (2012, p. 13)

Y luego, más en la tónica de la dialéctica ya vista anteriormente en Agustín entre libre arbitrio/determinación y gracia, agrega: "También ambos discursos (el psicoanalítico y el bíblico) sostienen que sólo si el Otro elige al sujeto como objeto de deseo, y lo erotiza y le dirige la palabra de la Ley, podrá éste constituirse a su vez como sujeto de discurso (...) los psicoanalistas podemos pensar ahora la figura de Dios como el Nombre del lenguaje mismo, y nuestra práctica nos permite acceder así a la producción de la Verdad (...) reconocer creativamente la nada (...)". (destacado propio, pp. 13-14)

Podemos entonces decir, luego de consignar este punto de acuerdo entre ambos registros, que, con la terminología explícitamente prestada de San Agustín, Lacan desarrolló la cuestion del das Ding ("la Cosa"), no sólo leyendo Freud y Heidegger, sino fundamentalmente adeudando al Padre de Hipona sobretodo en lo que atañe a la intimidad de lo extraño en el centro del yo. Ya vimos la importancia del oxímoron y la antítesis como figuras retóricas de representación dialéctica en un principio con elementos contradictorios ("sensibilidad insensible", etc). Como afirma Le Brun en su estudio sobre el amor puro, cuando Lacan habla de la Cosa como la nada en términos representacionales, "(...) si hace falta usar una metáfora topológica, es el lugar más interior y exterior a la vez" (Le Brun, 2004, p. 392) y luego agrega "el interior íntimo meo, para retomar las palabras de San Agustín cien veces citada por los espirituales, es también un lugar 
'abierto', 'faltante' (...)" (destacado en el original, p. 393).

En el marco filosófico que actualizaba la discusión con el Dios muerto de Nietzsche, antes, (aproximadamente una década antes), la desaparición de la "garantía del Padre" también fue un tema de Lacan en sus seminarios del 13 de enero y del 23 de marzo de 1960. Incluso, ante la sorprendida audiencia en tanto psicoanálisis presentado como necesariamente ateo. Aquí las palabras de Lacan:

(...) ¿Acaso la Ley es la Cosa? iOh, no! Sin embargo, sólo tuve conocimiento de la Cosa por la Ley. En efecto, no hubiese tenido la idea de codiciarla si la Ley no hubiese dicho - Tu no la codiciarás. Pero la Cosa encontrando la ocasión produce en mi toda suerte de codicias gracias al mandamiento, pues sin la Ley la Cosa está muerta. Ahora bien, yo estaba vivo antaño, sin la Ley. Pero cuando el mandamiento llegó, la Cosa ardió, llegó de nuevo, mientras que yo encontré la muerte. Y para mí, el mandamiento que debía llevar a la vida resultó llevar a la muerte, pues la Cosa encontrando la ocasión me sedujo gracias al mandamiento y por él me hizo deseo de muerte. Pienso que, desde hace un momentito, algunos de ustedes al menos, dudan de que sea yo quien sigue hablando. En efecto, con la salvedad de una muy pequeña modificación cosa en lugar de pecado-, este es el discurso de san Pablo en lo concerniente a las relaciones de la ley y del pecado, Epístola a los Romanos, capitulo
7, párrafo 7. Mas allá de lo que se piense de ellos en ciertos medios, se equivocarían al creer que los autores sagrados no son una buena lectura. En lo que a mi respecta, al sumergirme en ellos sólo encontré recompensas y, muy especialmente en éste, que les indico como deberes de vacaciones, encontrarán una compañía bastante buena ${ }^{7}$. (1960, p. 45)

En relación con la Cosa también nos interesa comprender estas religiosidades inconscientes anidadas en pensamientos notables de la laicidad del siglo XX. Entonces, pensando en el Mal y también en la Cosa, Lacan se pregunta cómo se puede abordar este tema

Dado que Dios surgió debido a que el padre ha muerto, sin duda quiere decir que nos hemos dado cuenta (...) de que Dios ha muerto; pero igualmente, dado que comunica con el padre muerto en el origen, él también estaba muerto desde siempre" y agrega que la cuestión del "creador en Freud plantea saber lo que sucede (...) de dónde debe colgarse lo que sigue ejerciéndose en ese orden, es decir, la ciencia. (Lacan, citado en Le brun, 2004. pp. 395-396)

Luego de esta crítica fulminante de Dios como esencia, Lacan trabaja el goce místico como acceso privilegiado al Otro como función y efecto. Esto, además, le permitirá ironizar sobre la condición de creyente incluso de los ateos y repetirá en varias oportunidades su concepción del cristianismo como la religión verdadera -esto es, porque permite mantener el hiato, la hendidura entre el sujeto y el

7 La amplitud de la cita obedece a los fines reiterativos que refuercen la idea de las lecturas de Lacan y su importancia en el marco de los seminarios que dictaba. 
sentido, el "misterio" que para Lacan iba a ser que jamás el psicoanálisis pueda triunfar por sobre la religión. Como dice en su Triunfo de la religión, "La ciencia, que es lo nuevo, introducirá montones de cosas perturbadoras en la vida de cada uno. Sin embargo, la religión, sobre todo la verdadera, tiene recursos que ni siquiera podemos sospechar. Por ahora basta ver cómo bulle. Es algo absolutamente fabuloso". (1960, p. 79)

Y años más tarde, también admitiendo este triunfo de la religión sobre el psicoanálisis, en principio, haciendo juego de palabras entre "dire" (decir) y "dieu" (Dios), al momento en que dice que "(...) en tanto se diga algo, allí estará la hipótesis de Dios" (1973,p. 43).

No es la única vez que menciona al cristianismo como "la religión verdadera", ni tampoco que admite la prevalencia del Otro del lenguaje en abierta sintonía con la posición judía de ocultamiento del Nombre de Dios, que en un punto es el Nombre de los nombres:

A mí me parece manifiesto que el Otro, presentado en la época de Instancia de la letra como lugar de la palabra, era una manera, no diré de laicizar, pero sí de exorcizar al buen Dios. Después de todo, hay mucha gente que me felicita por haber sabido postular en uno de mis últimos seminarios que Dios no existe. Evidentemente oyen, oyen, pero desafortunadamente comprenden, y lo que comprenden es un poco precipitado. Tal vez hoy les muestre más bien por qué existe justamente el buen Dios". (p. 63)

Es decir, que, aunque parezca disonante la aceptación de la caída de la última garantía de la existencia con la muerte del Padre con la posterior reivindicación de Dios como inconsciente en el marco de su ex-sistencia, vemos que los dos desarrollos de Lacan no son contrapuestos entre sí-justamente por la notable capacidad de influencia que tiene lo que permanece ajeno al campo ("ex") sobre el terreno donde actúa ("sistere").

A pesar de habernos únicamente detenido en estas influencias de Agustín en Lacan, no sería sólo esa la influencia del pensamiento católico en el pensador francés. Baste recordar, también, sus aportes en la lectura del jansenita Pascal, sobre todo en lo referente a la retórica oximorónica y contradictoria en los términos del autor de Pensamientos. Es deber de un próximo rastreo elucidar estas referencias. Por lo pronto, en palabras de la propia Vassallo, podemos indicar que para Pascal, el sujeto de la ciencia parte de bases tan 'incomprensibles' para la razón (los axiomas, el infinito) como el teólogo (el pecado original, por ejemplo, es tan incomprensible, en sí mismo, como los axiomas de la geometría, pero es ese incomprensible lo que hace comprender. Para Pascal, el significante existe antes que la razón. Se entiende así que, atrapado entre lo incomprensible y lo comprensible, el sujeto de la ciencia y de la teología estén ambos regidos por una misma ley (la división). (s/f, en línea: http://www.imagoagenda.com/articulo. asp?idarticulo $=1620$ )

Identificar y problematizar el trazo de las lecturas realizadas por pensadores que, sea en el campo que fuera, han hecho gala de laicidad y ateísmo, implica también reconocer las implicancias teóricas y prácticas de desembarazarse de las "tradiciones" sin pasar por un atravesamiento conclusivo y concluyente. Los apasionantes desafíos al pensamiento que supone la actualidad global y las 
reiteradas crisis permiten traer al presente debates pretéritos no con finalidades autosuficientes sino para darles sustento histórico a las necesarias actualizaciones categoriales.

\section{Bibliografía}

Benjamin, W. (2008) Tesis sobre la historia y otros fragmentos, España: Itaca.

Bernstein, R. (2002) Freud y el legado de Moisés, México: Siglo XXI.

Eagleton, T. (2006) La estética como ideología, Madrid: Trotta.

Eagleton, T. (2012) Razón, fe y revolución, Barcelona: Paidós.

Freud, S. (1959) Moisés y la religión monoteísta, Buenos Aires: Losada.

Freud, S. (1972) Tótem y tabú, Madrid: Alianza editorial.

Jameson, F. (1989) Documentos de cultura, documentos de barbarie, Madrid: Visor.

Lacan, J. (1960) Las pulsiones y los sueños, Clase 7, Seminario 7, en línea: http:// www.bibliopsi.org/docs/lacan/09\%20 Seminario\%207.pdf

Lacan, J. (2006) El triunfo de la religión, Buenos Aires: Paidós.

Lacan, J. (1973) El amor y el significante, Clase 4, Seminario 20, en línea: https:// agapepsicoanalitico.files.wordpress. com/2013/07/lacan-seminario-20-aun. pdf

Le Brun, J. (2010) El amor puro. De Platón a Lacan, Buenos Aires: El cuenco del Plata.

Milmaniene, J. (2006) Ética y transmisión paterna, en Revista Actualidad Psicológica, Año XXXI, No 348 , diciembre.

Milmaniene, J. (2012) La fe en el nombre. Una lectura psicoanalítica de las creencias, Buenos Aires: Biblos.

Pascal, B. (1964) Pensamientos. Buenos Aires: Losada.

Vassallo, S. (2015) La gracia y el deseo. San Agustín, Pascal, Lacan, Rosario: Nube Negra. 